\title{
Sweat electrolytes in patients with gastro-duodenal disease
}

\author{
R. L. TOZER ${ }^{1}$ \\ From the Department of Medicine, University of Western Australia, \\ Perth, Western Australia
}

EDITORIAL SYNOPSIS No alteration of sodium and potassium concentration in sweat has been uncovered in a group of patients with gastric and duodenal disease. These results do not suggest any genetic linking between fibrocystic disease of the pancreas and gastro-duodenal disease.

Since the recognition of fibrocystic disease of the pancreas by Andersen (1938) there have been several reports linking this disease with peptic ulcer. These reports have emphasized the prevalence of peptic ulcer in patients with fibrocystic disease and their relatives. Andersen (1958) noted that duodenal ulcer was a fairly common finding in her patients over 3 or 4 years of age. Koch (1959), in a study of close relatives of patients with fibrocystic disease, found an incidence of peptic ulcer of 20 to $30 \%$, some ten times greater than in the normal population.

One of the biochemical abnormalities in fibrocystic disease has been shown to be abnormally high sweat electrolyte concentrations (Darling, DiSant'Agnese, Perera, and Anderson, 1953). Koch (1959) reported that in a group of 31 unselected peptic ulcer patients, nine had raised sweat electrolytes, in the range expected in fibrocystic disease. It was considered important therefore to investigate sweat electrolyte levels in a series of patients with various gastro-duodenal diseases, without manifestations suggesting fibrocystic disease.

\section{MATERIAL AND METHODS}

One hundred and seventy subjects were studied. They were divided into six groups.

GROUP 1 Forty-three subjects (26 females, 17 males of age range 18 to 85 years), without evidence of upper gastro-intestinal disease, were mainly hospital employees and convalescent orthopaedic patients. They served as a control group.

GROUP 2 Forty-three subjects (14 females, 29 males of age range 28 to 84 years) had radiologically or operatively proven duodenal ulcer.

'James and Sith Annie Chesters scholar.
GROUP 3 Thirty-nine subjects (13 females, 26 males of age range 17 to 79 years) had radiologically or operatively proven gastric ulcer.

GROUP 4 Twenty-five subjects ( 20 females, five males of age range 33 to 85 years) with atrophic gastritis proven at biopsy or with pernicious anaemia, since this is known to be associated in adults with gastric atrophy or atrophic gastritis (Joske, Finckh, and Wood, 1955).

GROUP 5 Fifteen subjects (eight females, seven males of age range 33 to 61 years) were a miscellaneous group with $x$-ray negative dyspepsia and normal or but mildly abnormal gastric biopsy findings.

GROUP 6 Five subjects (all males of age range 52 to 79 years) had carcinoma of the stomach.

\section{METHOD}

Localized sweating was induced by the method described by Gibson and Cooke (1959) utilizing pilocarpine by iontophoresis. All materials used were rendered salt free by repeated washing in double-distilled water. The sweat was collected on a filter paper, which had been weighed previously in a test tube. After reweighing following sweat collection, double-distilled water (10 to $25 \mathrm{ml}$, depending on weight of sweat obtained) was added and the level of sodium and potassium in the diluting fluid estimated by flame photometry.

\section{RESULTS}

Results are shown in Table I and Figures 1 and 2. For technical reasons sweat potassium could not be measured in all patients, and the number of estimations is included in Table I.

The results were unaffected by the sex of patients.

Taking the results as a whole, the figures were unaffected by gastric or duodenal pathology, the 


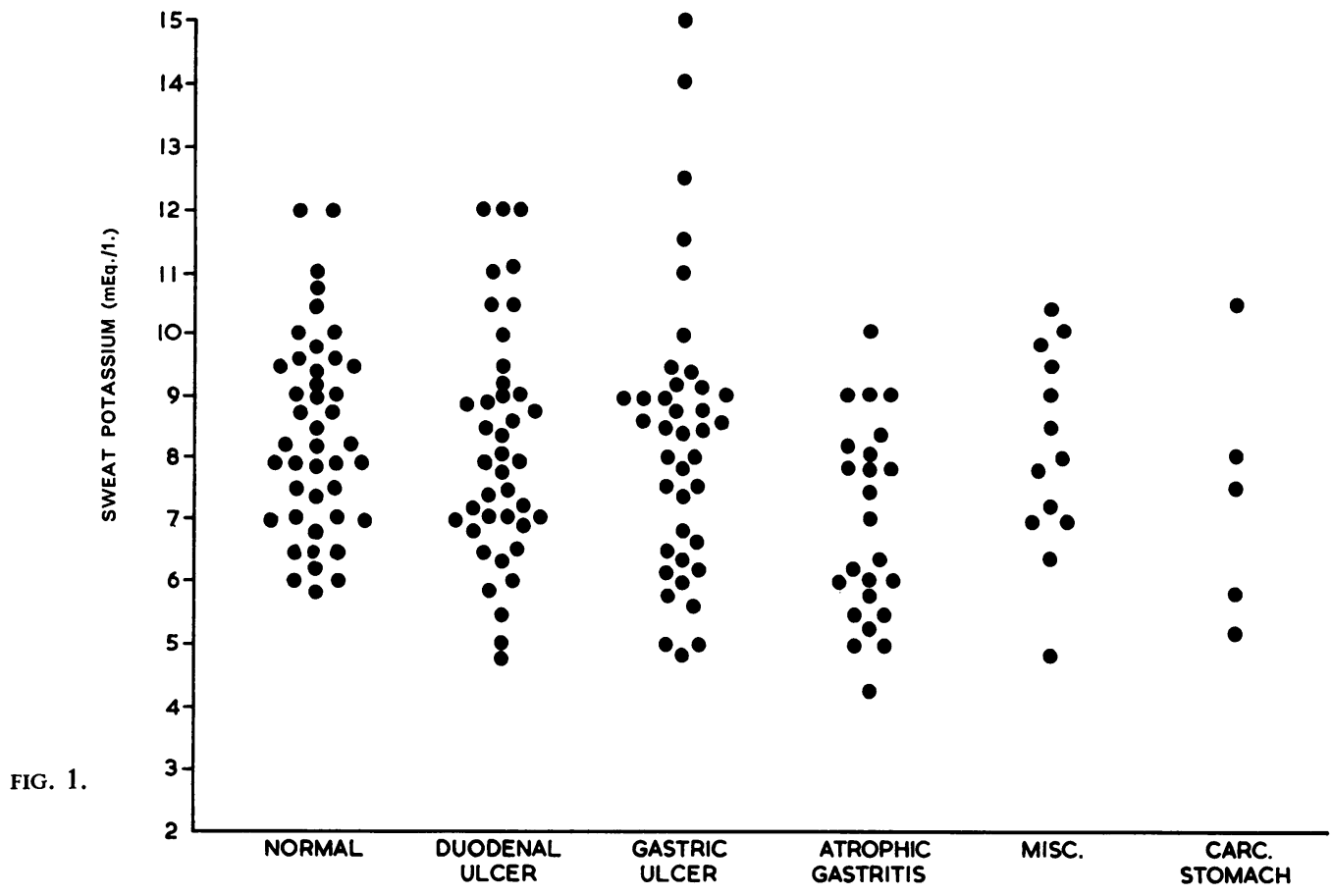

FIG. 2.

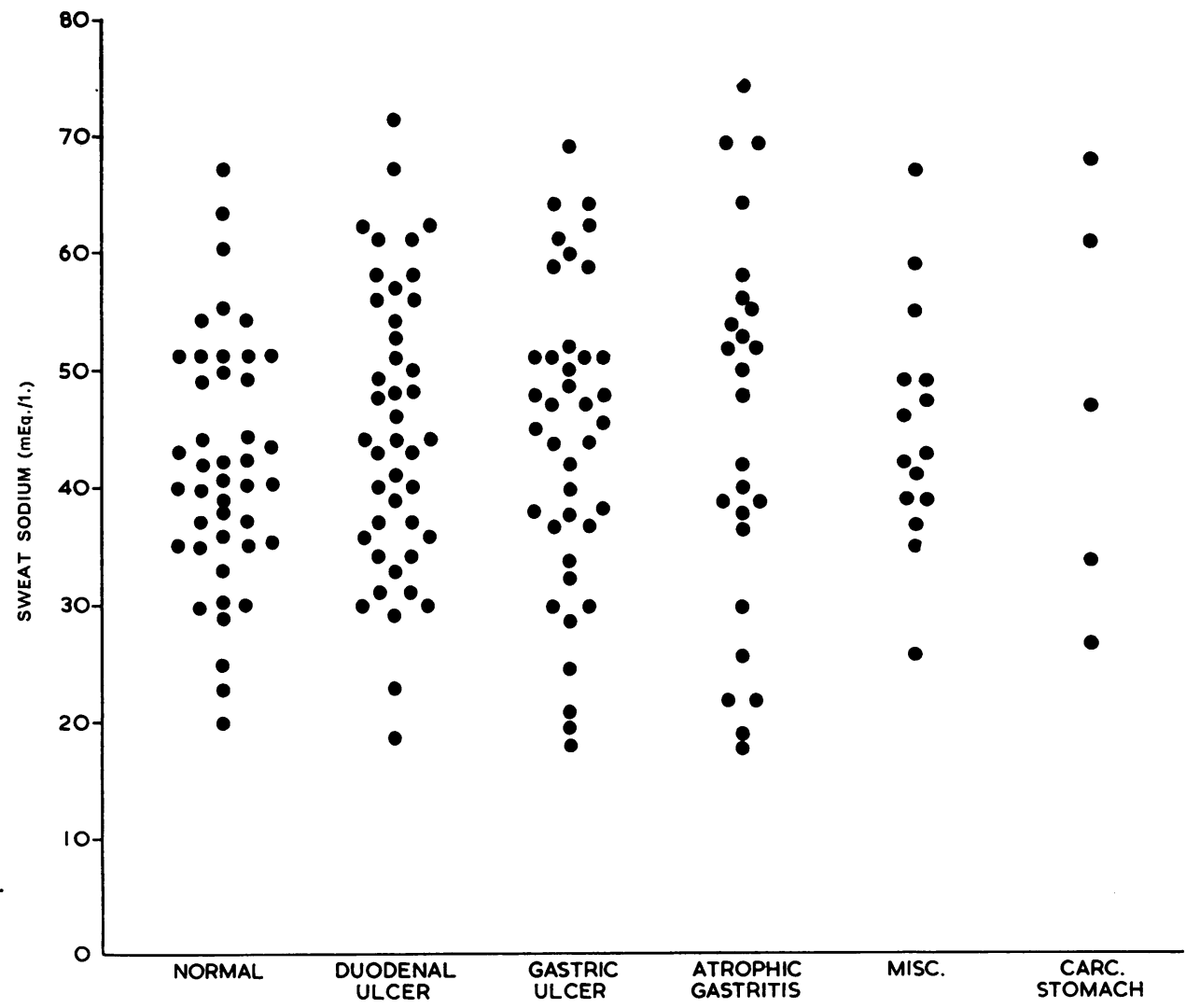


TABLE I

SWEAT SODIUM AND POTASSIUM CONCENTRATIONS IN NORMAL SUBJECTS AND PATIENTS WITH GASTRO- DUODENAL DISEASES

\begin{tabular}{|c|c|c|c|c|c|c|}
\hline \multirow{2}{*}{ Diagnostic Group } & \multicolumn{3}{|c|}{ Sweat Sodium ( $m E q . / l)}$. & \multicolumn{3}{|c|}{ Sweat Potassium (mEq./l.) } \\
\hline & $\begin{array}{l}\text { No. of } \\
\text { Subjects }\end{array}$ & Mean $\pm S . D$. & Range & $\begin{array}{l}\text { No. of } \\
\text { Subjects }\end{array}$ & Mean $\pm S . D$. & Range \\
\hline Normal control & 43 & $\begin{array}{r}42.6 \\
+10.9\end{array}$ & $20-67$ & 43 & $\begin{array}{r}8 \cdot 4 \\
\pm 1 \cdot 8\end{array}$ & $5 \cdot 8-12 \cdot 0$ \\
\hline Duodenal ulcer & 43 & $\begin{array}{r}44 \\
+12.0\end{array}$ & $19-72$ & 40 & $\begin{array}{r}8.0 \\
\pm 1.9\end{array}$ & $4 \cdot 8-12 \cdot 0$ \\
\hline Gastric ulcer & 39 & $\begin{array}{r}45.6 \\
+10.6\end{array}$ & $18-68$ & 39 & $\begin{array}{r}8 \cdot 1 \\
\pm 2 \cdot 0\end{array}$ & $4 \cdot 8-15 \cdot 0$ \\
\hline $\begin{array}{l}\text { Atrophic gastritis and } \\
\text { pernicious anaemia }\end{array}$ & 25 & $\begin{array}{r}47 \cdot 3 \\
+15 \cdot 8\end{array}$ & $18-74$ & 24 & $\begin{array}{r}7 \cdot 0 \\
\pm 1 \cdot 5\end{array}$ & $4 \cdot 2-10 \cdot 0$ \\
\hline Radiologically negative dyspepsia & 15 & $\begin{array}{r}44.6 \\
+\quad 8.8\end{array}$ & $26-67$ & 13 & $\begin{array}{r}8 \cdot 2 \\
\pm 2 \cdot 0\end{array}$ & $5 \cdot 0-10 \cdot 4$ \\
\hline Gastric carcinoma & 5 & $-47 \cdot 4$ & $27-68$ & 5 & $7 \cdot 4$ & $5 \cdot 2-10 \cdot 5$ \\
\hline
\end{tabular}

mean values for both sodium and potassium in all groups being statistically similar to those of the control groups.

\section{DISCUSSION}

These results show that sweat electrolytes are not increased in patients with gastro-duodenal disease and provide no evidence that these entities are genetically related to fibrocystic disease.

If this is so, there are at least three possible explanations for the reported high incidence of duodenal ulcer in patients with fibrocystic disease. Poth and Fromm (1952) have suggested deficient neutralization of acid in the duodenum in cases of pancreatic insufficiency as a factor in the production of peptic ulcer. This situation is analogous to that produced in dogs by Mann and Williamson (1923), who demonstrated the development of duodenal ulcers in their animals after the diversion of pancreatic secretions from this part of the intestine. The second possible explanation is abnormality in the mucus produced by patients with fibrocystic disease. The third possibility is that the peptic ulceration is a result of respiratory insufficiency, since Green and Dundee (1952) and others have shown an increased frequency of peptic ulcer in patients suffering from chronic bronchitis and emphysema. Sweat electrolytes have been shown to be within normal limits in these conditions (McKendrick, 1962). The reported increased incidence of peptic ulcer in relatives of patients with fibrocystic disease may be due to a proneness to peptic ulceration in heterozygote carriers of fibrocystic disease.

I wish to thank Dr. R. A. Joske, of the Department of Medicine, University of Western Australia, for his advice and encouragement, and Dr. D. H. Curnow, head of the Department of Biochemistry, Royal Perth Hospital, for his help and the use of laboratory facilities.

\section{REFERENCES}

Andersen, D. H. (1938). Cystic fibrosis of the pancreas and its relation to celiac disease; a clinical and pathological study. Amer. $J$. Dis. Child., 56, 344-399.

- (1958). Cystic fibrosis of the pancreas. J. chron. Dis., 7, 58-90.

Darling, R. C., DiSant'Agnese, P. A., Perera, G. A., and Andersen, D. H. (1953). Electrolyte abnormalities of the sweat in fibrocystic disease of the pancreas. Amer. J. med. Sci., 225, 67-70.

Gibson, L. E., and Cooke, R. E. (1959). A test for concentration of electrolytes in sweat in cystic fibrosis of the pancreas utilizing pilocarpine by iontophoresis. Pediatrics, 23, 545-549.

Green, P. T., and Dundee, J. C. (1952). The association of chronic pulmonary emphysema with chronic peptic ulceration. Canad. med. Ass. J., 67, 438-439.

Joske, R. A., Finckh, E. S., and Wood, I. J. (1955). Gastric Biopsy. A study of 1,000 consecutive successful gastric biopsies. Quart. J. Med., 24, n.s., 269-294.

Koch, E. (1959). Die erbliche Erwachsenen-Mucoviscidosis und ihre Beziehungen zur Ulkuskrankheit. Disch. med. Wschr., 84, 1773-1784.

McKendrick, T. (1962). Sweat sodium levels in normal subjects, in fibrocystic patients and their relatives, and in chronic bronchitic patients. Lancet, 1, 183-186.

Mann, F. C., and Williamson, S. C. (1923). The experimental production of peptic ulcer. Ann. Surg., 77, 409-422.

Poth, E. J., and Fromm, S. M. (1952). Relation of pancreatic secretion to peptic ulcer formation. Southwest Med., 33, 16-18. 